\section{Caminhos, pegadas e memórias: uma história social do Movimento Negro Brasileiro*}

\author{
Paths, footprints and memories: a social \\ history of the Brazilian Black Movement
}

\section{Resumo}

Este texto foi produzido com base em uma pesquisa realizada no ano de 2014 com o Movimento Social Negro no âmbito do Brasil. O objetivo foi investigar o Movimento Social Negro contemporâneo a partir dos marcos históricos e da memória desta luta registrada em diversos documentos . A metodologia utilizada neste artigo foi documental e exploratória, por meio de livros, documentos e websites conseguimos elaborar um texto que tem como ponto principal um quadro de memória do Movimento Social Negro brasileiro e sua história de luta e resistência.

Palavras-chave: História. Memória. Movimento Social Negro brasileiro.

\begin{abstract}
This text was produced based on a survey conducted in 2014 with the Black Social Movement in the Brazil. The objective was to investigate the Social Movement Black contemporary from the landmarks and the memory of this struggle recorded in various documents. The methodology used in this article was documentary and exploratory, through books, documents and websites could draft a text that has as its focal point a memory picture of the Brazilian Black Social Movement and its history of struggle and resistance.
\end{abstract}

Keywords: History. Memory. Social Brazilian Black Movement. 


\section{Introdução}

Entendemos com Petrônio Domingues (2007) por Movimento Social Negro a luta dos negros na perspectiva de resolver seus problemas na sociedade como um todo, em particular os provenientes dos preconceitos e das discriminações raciais, que os marginalizam nos mais diversos espaços sociais. Poderíamos rememorar a história do Brasil e verificar que as experiências de luta da população negra brasileira acontecem desde a formação dos primeiros quilombos; das revoltas das quais os africanos escravizados e seus descendentes foram protagonistas; das irmandades de santo; clubes e agremiações; da denúncia ao racismo pela imprensa negra e tantas outras formas de resistência à escravidão e, por conseguinte, a violência de toda ordem. Podemos, ainda, atestar a conceituação dada por Joel Rufino dos Santos (1994), quando este nos diz que Movimento Negro é:

[...] todas as entidades, de qualquer natureza, e todas as ações, de qualquer tempo [aí compreendidas mesmo aquelas que visavam à autodefesa física e cultural do negro], fundadas e promovidas por pretos e negros [...]. Entidades religiosas [como terreiros de candomblé, por exemplo], assistenciais [como as confrarias coloniais], recreativas [como "clubes de negros"], artísticas [com os inúmeros grupos de dança, capoeira, teatro, poesia], culturais [como os diversos "centros de pesquisa"] e políticas [como o Movimento Negro Unificado]; e ações de mobilização política, de protesto anti-discriminatório, de aquilombamento, de rebeldia armada, de movimentos artísticos, literários e 'folclóricos' - toda essa complexa dinâmica, ostensiva ou encoberta, extemporânea ou cotidiana, constitui movimento negro (SANTOS, 1994, p. 157).

Mas, para além do já mencionado por Rufino e Domingues, e seguindo o movimento da história do Brasil, o trato com os africanos e seus descendentes, adentramos nas particularidades desse Movimento Negro, no sentido de compreendê-lo, também, como um movimento político de mobilização racial (negra), que, em dados momentos, assume uma face fundamentalmente cultural, que se molda conforme a conjuntura sem perder de vistas seus princípios e a sua bandeira maior que é o combate ao racismo.

Com base nesse caminho, este artigo se norteou. A proposta metodológica utilizada para construir este artigo visou a priori pesquisar documentos e produções acadêmicas (bibliografia), a fim de buscar um histórico do Movimento Negro. Em segundo momento, foi realizada a pesquisa de campo nas redes sociais mapeando as lideranças que atuam no Movimento Negro nas regiões pesquisadas com o propósito de criar um quadro demonstrativo. A Rede Mundial de Computadores, ou seja, a internet foi utilizada como instrumento de pesquisa, a qual foi uma importante ferramenta, sobretudo na busca de informações e produções que envolviam o tema da diversidade étnico-racial, Movimento Negro e a educação, a partir de pesquisa com as palavras-chave: Lei $\mathrm{n}^{\circ}$ 10.639/03 e Movimento Negro.

Finalmente, elaborou-se uma proposta de quadro demonstrativo em que apareciam as organizações negras e as lideranças do Movimento Negro em cada região.

\section{Um olhar para o Movimento Social Negro do passado, do presente rumo ao futuro}

Corremos o risco de contestação devido às muitas possibilidades de se estabelecer uma periodização para a história do Movimento Social Negro em âmbito nacional, mas sabemos, também, que não é nosso propósito acerca do tema explorá-lo e esgotá-lo, tampouco estabelecer verdades estáticas dissociadas da sua historicidade. No entanto, é possível afirmar que, grosso modo, o Movimento Social Negro teve ao longo de séculos uma existência pautada por altos e baixos, algo bastante comum em se tratando de um movimento social bastante controverso e complexo, ainda mais quando estamos nos referindo a um movimento social que necessitou lutar pelo reconhecimento de sua maior bandeira de luta que é o combate ao racismo.

É de notório saber que os cinco séculos de presença negra no Brasil foram marcados por grandes batalhas pela liberdade e pela preservação da cultura de matriz africana, pela igualdade de direitos, por direitos humanos, pois, quanto mais aumenta a consciência da população pelos seus direitos, aumenta, também, a busca por educação como um direito social. Nesse caminho, precisa-se lembrar que essa perspectiva de movimento com o qual buscamos dialogar, historicizar e analisar não é estático e engessado num dado tempo histórico, ao contrário, enquanto conceito é complexo e dinâmico, de forma que não existe uma única teoria interpretativa de tal fenômeno social, ou mesmo um modelo cristalizado de concepção de movimento social.

O caminho histórico que segue o Movimento 
Social Negro é regido por muitas lutas, muita violência, muitas derrotas, algumas importantes vitórias e muitas memórias a serem reconstituídas. Esse movimento, que na contemporaneidade sobrevive, nasce como forma de resistência à violência provocada pelo escravismo criminoso quando, de acordo com Moura (1988) e Reis e Silva (1989) os grupos de africanos fugiam do eito e se organizavam em comunidades denominadas de quilombo. O quilombo representou somente uma das formas de resistência e combate ao escravismo criminoso contra os africanos e seus descendentes na diáspora negra. Sua formação visava à rejeição contra a condição de escravização imposta aos africanos. Além dos quilombos, foram muitas as formas de resistência à escravidão negra, quer seja coletiva ou individual. A exemplo das revoltas (Malês/ BA, Balaiada/MA), importantes eventos tiveram a participação dos afrodescendentes. Como também podemos mencionar as irmandades de santo (Nossa Senhora da Boa Morte/BA - por volta de 1820); Irmandade de (Nossa Senhora do Rosário - Caicó/RN - 1680); São Benedito dos Homens Pretos (RJ, 1640), bem como os clubes e agremiações; a imprensa negra e tantas outras formas de resistência e luta pela abolição da escravatura.

Falamos, até aqui, de um primeiro momento do Movimento Social Negro. Em segundo momento, verifica-se, com base nos registros históricos, o pós-abolição, ou o dia seguinte ao 13 de maio de 1888 , quando milhares de negros e negras se viram libertos e sem ter o que fazer com a tal liberdade, sem ter o amparo do Estado. Inicia-se, assim, um longo processo de luta para se ter acesso aos bens e aos serviços e desfrutar de tudo que a nação produzia. É a partir desse momento histórico que vamos verificar na literatura uma série de eventos, como a Revolta da Chibata (1910) liderada por João Candido marinheiro negro, no Rio de Janeiro, que se opôs ao modo como eram tratados os marujos da marinha brasileira; A Frente Negra Brasileira (1931-1937), associação de caráter político, recreativo e beneficente, surge, em São Paulo, com intenções de se tornar uma articulação nacional e, em 1936, se transforma em partido político. Porém, o Decreto ${ }^{\circ}$ 37, de 2 de dezembro de 1937 (BRASIL, 1937), assinado pelo então Presidente Getúlio Vargas, que colocava na ilegalidade todos os partidos políticos, acabou ocasionando sua extinção.

Outra forma de luta também importante foi a impressa negra, que conseguiu grande apoio na comunidade negra, difundindo aquilo que os seus redatores achavam mais importante para a vida social e cultural dos negros. Nesse caminho histórico, encontramos, ainda, o Teatro Experimental do Negro (TEN) (1944-1968), na cidade do Rio de Janeiro. O TEN tinha como propósito um trabalho voltado para a valorização social do negro no Brasil, por meio da educação, da cultura e da arte (NASCIMENTO, 2004).

Esse Movimento Social Negro que traz impresso no seu histórico uma enorme bandeira de luta contra o racismo e seus derivados, de acordo com os apontamentos de Gomes (2011), inaugura importantes fases, opostas no sentido acadêmico, porém, numa direção política e organizativa que as fortalece e, culminam com o que nos chega à contemporaneidade. Todavia, é importante salientar, ainda, de acordo com Gomes (2011, p. 141) que:

[...] cada uma dessas organizações viveu processos de tensão interna, contradições, conflitos, assim como todas as ações emancipatórias presentes nas sociedades. No entanto, podemos dizer que, a luta contra a escravidão, no passado, e a superação do racismo e da discriminação racial, no presente, são pontos comuns na história das populações negras organizadas no Brasil e na América Latina.

Os anos de 1950 e 1960 são marcados por uma série de acontecimentos externos ao Brasil, mas que refletem com muita força em todo país. O mundo vive o pós Segunda Guerra Mundial, com a criação da Organização das Nações Unidas (ONU) em 1945, quando o cenário mundial ainda abalado com as atrocidades provocadas pela Guerra, traz à tona as discussões acerca dos direitos humanos. O racismo e o antissemitismo evidenciado após a Segunda Guerra precisam ser vistos pelo mundo como um tema a ser combatido. Hannah Arendt (apud LAFER, 1991) resume esse contexto afirmando que os homens não são iguais, como formulado no artigo $1^{\circ} \mathrm{da}$ Declaração Universal dos Direitos Humanos de 1948. Mas se tornam iguais como membros de uma coletividade em virtude de uma decisão conjunta que garante a todos direitos iguais. A igualdade, portanto, não é um dado, é uma construção elaborada convencionalmente pela ação dos homens enquanto cidadãos de uma comunidade política.

Ainda nesse contexto histórico, a luta por igualdade de direitos e pela descolonização ganha a consciência mundial. Trata-se de uma conjuntura em que ganha força as políticas de ações afirmativas. Nos anos que sucederam o processo de descolonização da África, Américas e Ásia, as populações nativas dos países envolvidos verificaram a 
necessidade de um apoderamento efetivo dos seus países, das suas terras. Naquele momento histórico, os países que saíam dos domínios da Europa tiveram que se defrontar com o urgente problema de substituir em tempo relativamente curto, os europeus que dantes monopolizavam todos os postos de comando da sociedade, inclusive a rede de ensino, pelos nativos, os verdadeiros donos das terras. Os povos africanos, asiáticos e americanos deram o direcionamento à ordem vigente para a reintegração, posse e direção políticas dos seus países foi a chamada "indigenização" ou "nativização". Esse foi o rótulo aplicado, mas, na realidade, era uma política afirmativa que estava sendo aplicada em escala mundial (SILVA, 2011).

O Brasil, assim como o resto do mundo, vivia momentos de reflexões, ações e ebulições protagonizadas por grupos e segmentos sociais ditos minorias como mulheres, homossexuais, idosos, pessoas com deficiências, indígenas (MOORE, 2005).

Em 1964, o país iniciou um processo de repressão com a ditadura militar e toda a movimentação histórica, pós-abolição, foi pressionada pela então ditadura militar, instaurada naquele ano. Nesse cenário, de acordo com Gomes (2011), as formas organizativas de movimento foram obrigadas a sair do cenário público não somente a luta formal contra a discriminação racial, como também as demandas de todos os movimentos sociais, embora os sujeitos que as defendiam continuassem agindo contrariando o Estado autoritário.

Em fins dos anos de 1970, há um contexto de pressão pelo fim da ditadura militar e surge uma reorganização dos movimentos sociais. O Movimento Negro também se destacou nesse cenário quando, em 1978, se organizou o Movimento Negro Unificado (MNU), uma entidade nacional que marcou a história do Movimento Negro contemporâneo e foi considerada como um dos principais protagonistas na luta antirracista brasileira.

Após os anos de 1970, o Movimento Negro aprofundou a sua atuação e análise e o debate acerca do racismo no Brasil cresceu em número e pluralidade de inserção de intelectuais que tratam da temática. Intelectuais negros se apropriaram do debate e deram nova roupagem metodológica à abordagem do negro brasileiro, inclusive com propostas políticas importantes para a transformação da desigualdade racial.

A trajetória intelectual dos negros nas Américas é objeto importante de reflexão de inúmeros intelectuais, dentre os quais destacamos a de Paget Henry (2000) que observa que a afrofilosofia é um modo de intelectuais negros elaborarem suas concepções de mundo, quase sempre aliadas a uma prática política de transformação, em virtude da urgência da necessidade de inclusão nas esferas de poder.

Por razões históricas, a trajetória do negro no Brasil atravessou um processo de exclusão econômica, educacional e cidadã, que se refletiu na qualidade da inserção do negro nos espaços de poder, nas decisões políticas e nos campos de construção do saber. A compreensão de que os espaços de exclusão da sociedade brasileira não necessariamente dialogam ou discutem estratégias comuns faz com que, para cada espaço de exclusão do negro, seja necessária uma reflexão diferenciada.

A condição de desigualdade aliada à experiência de gênero, vividas no interior do próprio movimento negro, impulsionou as mulheres negras a se organizarem e a fundarem, nos anos de 1980, o Movimento das Mulheres Negras, que hoje é parte integrante da Articulação Latina e Caribenha de mulheres negras, bem como de outras organizações internacionais. Elas também estão à frente de organizações políticas importantes como as Organizações não Governamentais de Mulheres negras e os terreiros.

O ano de 1995 foi marcado pela comemoração ao tricentenário da morte de Zumbi dos Palmares, quando as diversas organizações do movimento negro brasileiro organizaram a Marcha Zumbi dos Palmares Contra o Racismo, pela Cidadania e a Vida, com a participação de mais de 20 mil pessoas, organizada pelo movimento negro e as organizações de esquerda. A Marcha aconteceu no mês de novembro daquele ano em Brasília.

De acordo com Silva (2007), ${ }^{2}$ podemos constatar que os anos 2000 foram marcados por uma série de eventos que conduziram a mudanças significativas, sobretudo no âmbito da legislação antirracista brasileira e da postura do Estado brasileiro, que trouxe uma nova marca na resistência e organização negra brasileira, a luta pelas políticas públicas de ação afirmativa.

Um marco importante foi a III Conferência Mundial contra o Racismo, a Discriminação Racial, a Xenofobia e Formas Correlatas de Intolerância (CMR) em Dur-

2 Nas fontes pesquisadas não foi registrado nenhum desembarque entre 1853 e 1855 . Apenas um navio transportando aparentemente 300 escravos chegou ao Rio de Janeiro em 1856. Vide: <http://www.enfpt.org.br/eol/timeline/timeline-primeira.php\#0>. Acesso em: 12 fev. 2014. 
ban, África do Sul - 2001. O Estado brasileiro conseguiu articular a ida de diversas organizações do Movimento Social Negro brasileiro e reconhecê-los como atores legítimos para os fenômenos racistas brasileiros, discutidos à luz das Convenções, Tratados e Conferências Internacionais. De todo esse debate, o governo brasileiro, representado pelo ex-presidente Fernando Henrique Cardoso, trouxe ao Brasil uma série de Programas de Combate ao Racismo e de equidade, a saber: a) o Programa Bolsa-Prêmio, do Instituto Rio Branco - Ministério das Relações Exteriores, criado em 2002; b) O Programa Diversidade na Universidade, criado em 2002, no Ministério da Educação; c) a inclusão dos quesitos cor e gênero nos programas de capacitação profissional do Ministério do Trabalho e no Ministério da Saúde.

Embora criados formalmente no ano de 2002, todos esses Programas passaram a ser executados no ano de 2003, logo após o final do mandato de um governo de oito anos. Com a mudança de governo, os Programas foram mantidos e incrementados com a criação da Secretaria Especial de Políticas de Promoção da Igualdade Racial (SEPPIR), ligada à Presidência da República; da homologação da Lei $n^{\circ} 10.639 / 2003$, que institui a obrigatoriedade da História e Cultura Afro-Brasileira na educação básica e altera a Lei de Diretrizes e Bases da Educação Brasileira (LDB); da implementação da Secretaria de Educação Continuada, Alfabetização e Diversidade (SECAD), no Ministério da Educação, com enfoque temático para as diversidades étnico-raciais e políticas de valorização nos sistemas de ensino. Também, no Ministério da Educação, ações importantes foram implementadas, como a Inclusão do quesito raça/cor no Censo Escolar, em 2005; criação do Programa Universidade para Todos (PROUNI), com cotas raciais e a formação de um Grupo de Trabalho, instituído pela Portaria No. 10, de 20 de março de 2006, pela Secretaria de Educação Tecnológica (SETEC), com a finalidade de implementar os artigos 26A e 79B da LDB, como, a temática da História e Cultura Afro-Brasileira e Africana nos currículos das escolas da rede federal de educação profissional e tecnológica (GEBRIM, 2006).

No âmbito do Movimento Social Negro, a Conferência Nacional contra o Racismo e a Intolerância, que aconteceu em julho de 2001, na Universidade do Estado do Rio de Janeiro (UERJ), marcou a construção de um consenso entre as diversas entidades do Movimento Social Negro sobre a necessidade de se implantar ações afir- mativas no Brasil. Uma instituição importante nesse momento foi o Instituto de Pesquisas Aplicadas (IPEA), que, com dados reais sobre o quadro de desigualdade no país com recorte de raça fortalece os argumentos das primeiras organizações negras do país, que já denunciavam no século XIX e demandado pelo Movimento Social Negro no século XX vem à tona as vistas do Estado tão somente no século XXI. E, de acordo com Gomes (2011, p. 143), “[...] passa finalmente a fazer parte da agenda política e do compromisso do Estado brasileiro com todos os avanços e as contradições possíveis".

Apesar de reconhecer os esforços empreendidos pelo Estado brasileiro sob a pressão do Movimento Social Negro - a fim de que seja implementada uma agenda afirmativa em prol da população negra neste país, Verifica-se, portanto, que as políticas afirmativas instituídas, em âmbito federal, não encontram suporte na ideologia administrativa das equipes gestoras dos diferentes níveis e modalidades de ensino provocam discrepâncias no atendimento aos alunos. Embora inseridos formalmente em Programas de Ações Afirmativas, alunos e professores precisam ser mobilizados rumo a uma agenda pedagógica de combate ao racismo e experimentação de estratégias integradas de inclusão social.

\section{Marcos positivos para o Movimento Social Negro Brasileiro: Pesquisa documental}

\section{Quadro 1}

1630. Data provável da formação do Quilombo dos Palmares. Palmares ocupou a maior área territorial de resistência política à escravidão, sediando uma das mais efetivas lutas de resistência popular nas Américas.

1833. Foi fundado o Jornal O homem de cor, por Paula Brito, sendo o primeiro periódico brasileiro a defender os direitos dos negros escravizados.

1850. Foi instituída a Lei Eusébio de Queirós, que proíbe o tráfico de negros escravizados pelo Oceano Atlântico. A lei, do Segundo Reinado, atendia a interesses da Inglaterra, mas foi fundamental para o processo de abolição da escravidão no Brasil.

1869. Proibida a venda de negros escravizados por "pregão" e com exposição pública. A lei também proíbe a venda em separado de membros de uma família (casais e pais e filhos).

1871. Instituída a Lei do Ventre Livre, estabelecendo que 
os filhos dos negros escravizados do Império, a partir daquela data, seriam considerados livres, depois de completarem a maioridade.

1884. Decretada a abolição da escravatura negra nas províncias do Amazonas e do Ceará, sendo as primeiras libertações coletivas de negros escravizados no Brasil.

1885. A Lei n ${ }^{\circ} 3270$ foi aprovada em 1885, e ficou conhecida como a Lei Saraiva-Cotegipe ou Lei dos Sexagenários, que regula a extinção gradual do elemento servil dos Sexagenários; concede liberdade aos negros escravizados com idade entre 60 e 65 anos, tendo sido promulgada em função do movimento abolicionista. ${ }^{3}$

1888. Promulgada, em 13 de maio, a Lei Áurea, extinguiu oficialmente a escravidão no País. O dia 13 de maio foi transformado pelo Movimento Negro Unificado - MNU, em "Dia Nacional de Denúncia contra o Racismo", após a fundação do Movimento Negro Unificado - MNU, no ano de 1978. A data é considerada pelo Movimento Negro como uma "mentira cívica", sendo caracterizada como Dia de Reflexão e Luta contra a Discriminação.

1889. Proclamação da República e a cidadania formal para negras e negros.

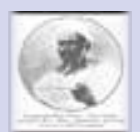

1910. João Cândido, o Almirante Negro, lidera a Revolta da Esquadra, também conhecida como Revolta da Chibata, pondo fim aos castigos físicos praticados contra os marinheiros.

1914. Surge em Campinas a primeira organização sindical dedicada à causa dos negros. Dela participaram, de forma expressiva e determinante, as mulheres negras.

1915. É fundado o jornal Menelick, o primeiro periódico paulista dedicado à difusão da cultura negra e à defesa dos interesses da população afrodescendente.

1931. Eleito o primeiro juiz negro do Supremo Tribunal Federal do Brasil: Hermenegildo Rodrigues de Barros, o criador do Tribunal Superior de Justiça Eleitoral.

1931. Criada a Frente Negra Brasileira, liderada por José

São libertos os escravos de 60 anos de idade, completos antes e depois da data em que entrar em execução esta lei, ficando, porém, obrigados a título de indenização pela sua alforria, a prestar serviços a seus ex-senhores pelo espaço de três anos. Os que forem maiores de 60 e menores de 65 anos, logo que completarem esta idade, não serão sujeitos aos aludidos serviços, qualquer que seja o tempo que os tenham prestado com relação ao prazo acima declarado. Disponível em: <http://www.direitoshumanos.usp.br/index.php/Documentos-Hist $\% \mathrm{C} 3 \% \mathrm{~B} 3$ ricos-Brasileiros/lei-dos-sexagenarios.html>. Acesso em: 24 fev. 2014.
Correia Leite, Arlindo Veiga dos Santos, Francisco Lucrécio e Raul Joviano do Amaral, entre outros, foi um movimento de repercussão nacional, de mobilização popular que saiu de São Paulo e atingiu outros estados do país, entre eles, Maranhão, Pernambuco, Sergipe, Bahia, Espírito Santo, Rio de Janeiro, Rio Grande do Sul e Minas Gerais. Editou o jornal A Voz da Raça no período de 1936 a 1938. Em 1936 transformou-se em partido político e foi fechada em 1937 com o golpe do "Estado Novo" de Getúlio Vargas.

1932. Criado em São Paulo o Clube do Negro de Cultura Social. Seus dirigentes editavam o jornal "O Clarim da Alvorada", um dos mais importantes na história do periodismo racial.

1937. Criação da Frente Negra Pernambucana numa "reação contra a proibição da visita de negros à Rua do Triângulo e da dança de negros em lugares considerados como de frequência para brancos. Em Pernambuco, a Frente Negra chegou com a visita de Barros, o "Mulato" do Rio Grande do Sul. Solano Trindade, José de Albuquerque, Gerson Monteiro de Lima criaram a "Frente Negra Pernambucana".

1940. Censo Demográfico Brasileiro desse ano apontou que negros eram $14 \%$, mulatos eram $21 \%$ e os brancos eram $65 \%$ da população evidenciando a política de branqueamento da população brasileira.

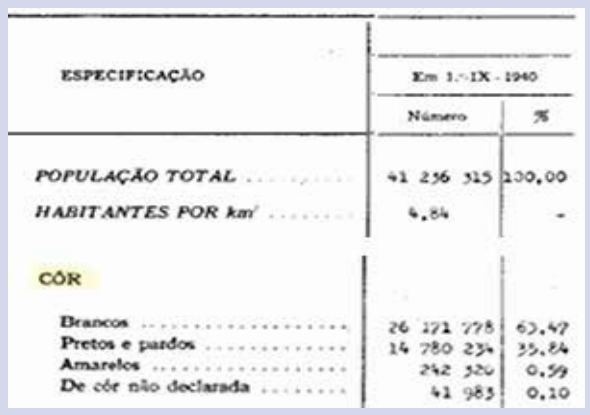

1944. Fundação do Teatro Experimental do Negro no Rio de Janeiro, por Abdias Nascimento, um dos maiores defensores da cultura e igualdade de direitos para as populações afrodescendentes no Brasil.

1945. Convenção Nacional do Negro Brasileiro reuniu propostas da comunidade negra para a Constituinte de 1946, entre elas a formulação de uma lei antidiscriminatória.

1945. Criada em São Paulo a Associação do Negro Brasileiro. No Rio, foi organizado o Comitê Democrático Afro-Brasileiro, para defender a Constituinte, a anistia e o fim da discriminação racial. Acontece a "I Convenção Negro-Brasileira".

1949. Conferência Nacional do Negro no Rio de Janeiro. O evento reuniu representantes de organizações negras de 
vários Estados como Minas Gerais, Rio de Janeiro, Bahia, Rio Grande do Sul, São Paulo.

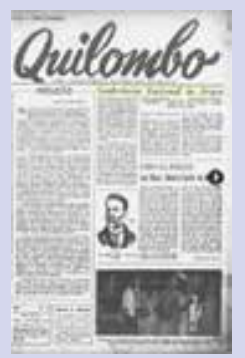

1949. Primeira página do jornal Quilombo, órgão informativo do Teatro Experimental do Negro, periódico mensal que circulou no Rio de Janeiro entre 1948 e 1950.

1951. É aprovada a Lei 1.390/51 ou Lei Afonso Arinos, que estabelece como contravenção penal a discriminação de raça, cor e religião. É também criado o Conselho Nacional de Mulheres Negra.

1954. Publicação do livro Preconceito racial de marca e preconceito racial de origem, De Oracy Nogueira, como parte do projeto de pesquisa da UNESCO sobre relações raciais no Brasil. Publicado em São Paulo/SP.

1955. Publicação do livro: "Negra e Branca" em São Paulo como parte do projeto de pesquisa da UNESCO sobre relações raciais no Brasil, em São Paulo /SP.

1960. Censo Demográfico Brasileiro. O Censo Demográfico Brasileiro coletou informação sobre cor e raça e apontou que negros eram $9 \%$, pardos eram $29 \%$, brancos eram $61 \%$ da população e amarelos era $1 \%$; evidenciando a política de branqueamento da população brasileira.

1960. Lançamento do livro Quarto de Despejo de Carolina Maria de Jesus, em São Paulo/SP.

1960. 21 de março é instituído como Dia Internacional pela Eliminação da Discriminação Racial demarcado pelo massacre de Sharpeville na África do Sul.

1961. Fundação da Associação dasEmpregadas Domésticas de Campinas - SP. Desde a fundação, o principal objetivo do sindicato é orientar as/os trabalhadoras/es em seus direitos, como também articular campanhas educativas e de mobilização estadual e nacional, fazer negociações articuladas, propiciar a troca de experiências entre os sindicatos, desenvolver políticas afirmativas na promoção de igualdade de oportunidades de gênero, combate à discriminação de raça, credo, idade e das minorias, inserir as trabalhadoras domésticas nas lutas gerais dos trabalhadores.

1963. Dia 25 de maio é o dia da África, instituído pela Organização dos Estados Africanos e ONU.

1963.02 de Dezembro é o Dia Nacional do samba.

1964. Publicação do livro A integração do Negro nas Sociedades de Classe de Florestan Fernandes - São Paulo/ SP.
1964. Prisão e tortura de Lima Azevedo do MPLA. Lima de Azevedo foi libertado após articulação diplomática com intervenção de Abdias Nascimento (correspondente oficial brasileiro do Movimento Popular Nacional de Libertação de Angola (MPLA)).

1965. Convenção 111 da OIT sobre discriminação no emprego e ocupações.

O Brasil assinou a Convenção 111 da OIT sobre discriminação no emprego e ocupações adotadas pela Conferência Internacional do Trabalho desde 1958, ratificada somente em 16/11/1965 no Governo Militar.

1965. Lançamento do livro O negro revoltado de Abdias Nascimento, publicado no Rio de Janeiro/RJ. O livro apresenta informações sobre os anais do I Congresso do Negro Brasileiro.

1968.0 Brasil assina a Convenção Internacional sobre a eliminação de todas as formas de discriminação racial adotada pela ONU desde 1965.

1968. A Câmara de Comércio Afro-Brasileira em São Paulo realiza intercâmbio comercial com alguns países da África seguindo a política internacional da Ditadura Militar.

1969. Lei de Segurança Nacional de 11/03/1967. A Lei de Segurança Nacional de 11/03/1967, em seu artigo $n^{\circ} 33$, item Vl, assinalava como crime contra a segurança do Estado Brasileiro incitar publicamente ao ódio ou à discriminação racial incluindo veiculação na imprensa, panfletos radiodifusão ou televisão. Isso, consequentemente, aumentou a repressão política dos ativistas da luta antirracista. A vigilância repressiva da Ditadura Militar contra as manifestações antirracistas está registrada no arquivo do DEOPS e SNI. Os órgãos repressivos acusavam os ativistas do movimento negro de incitar conflitos raciais existentes no exterior e eram veiculadores de propaganda "marxista".

1969. Fundação do Centro de Estudos Africanos da USP sob a direção de Clovis Moura, que organizava palestras e pesquisas acadêmicas juntamente aos Florestan Fernandes sobre a temática do negro brasileiro. Tinha suas atividades monitoradas pelo DEOPS/SP.

1970. Fundação do Centro de Cultura e Emancipação da Raça Negra (CECERNE) em Recife/PE.

1971. Fundação do Grupo Palmares de Porto Alegre/RS no mês de novembro. $O$ grupo realizou nesse ano, a semana de literatura Afro Brasileira onde, pela primeira vez, o poeta Oliveira Silveira (1941 - 2009) homenageia ZUMBI dos PALMARES e lança a base histórica para construção do DIA NACIONAL DA CONSCIÊNCIA NEGRA. 
1971. Fundação do Grupo Evolução de Campinas/SP que atuava na área político-cultural e mobilizava ativistas no interior de São Paulo.

1972. Fundação do Centro de Estudos e Arte Negra CECAN/SP.

1972. 1a Semana de Cultura Negra organizada no Rio de Janeiro pela Profa Beatriz Nascimento (1942 - 1995) reuniu ativistas que denunciavam as práticas racistas da época que contratavam com a euforia do chamado Milagre Brasileiro.

1973. Fundação do Centro de Estudos Afro-Asiáticos Universidade Candido Mendes - CEAA/RJ.

1974. Em Salvador, foi fundado o bloco afro llê Aiyê. Em São Paulo, aconteceu a Semana do Negro na Arte e na Cultura, que articulou apoio às lutas de libertação travadas na África. Surgiram várias entidades de combate ao racismo. Em São Paulo, foi criado o Centro de Estudos da Cultura e da Arte Negra (CECAN); o Movimento Teatral Cultural Negro; o Instituto Brasileiro de Estudos Africanistas (IBEA) e a Federação das Entidades Afro-Brasileiras do Estado de São Paulo. No Rio de Janeiro, surgiram o Instituto de Pesquisas da Cultura Negra (IPCN); a Escola de Samba Gran Quilombo e a Sociedade de Intercâmbio Brasil-África.

1974.Fundação do Jornal Árvore das Palavras. Uma produção clandestina de editorial pan-africanista para propaganda da luta antirracista no Brasil e as lutas de libertação da África. Teve edições que circularam por entre as cidades de São Carlos, Campinas e Capital de São Paulo.

1974. 1a Semana Afro-Brasileira do CEAA - Universidade Candido Mendes - Rio de Janeiro/RJ.

1975. Fundação da Federação das Entidades AfroBrasileiras do Estado de São Paulo/SP.

1975. Fundação do Teatro Popular Solano Trindade com sede na cidade de Embu das Artes/SP.

1975. Jornal Versus Seção Afro-Latino-América (12a à 24a edição). A jornalista Neusa Maria Pereira no lançamento da secção do Afro-Latino-América (n. 11 Jornal Versus) escreveu contundente manifesto em defesa da dignidade das mulheres negras em uma sociedade racista.

1976. Lançamento da Revista Tição editada em Porto Alegre/RS, que circulou entre 1976 a 1982.

1976. Curso de cultura negra no Brasil, organizado por Lélia Gonzalez (1935 - 1994), primeira mulher eleita para o Diretório Nacional do PT, realizado na Escola de Artes Visuais- RJ.
1976. O Governo do Estado da Bahia suprimiu a exigência de registro policial para o funcionamento dos templos religiosos de matriz africana, depois de grande mobilização popular.

1977. Fundação do Grupo Decisão formado por ativistas como Hamilton Cardoso, Rafael Pinto, Milton Barbosa e outros (as) /SP.

1977. Formação do Núcleo Negro Socialista. Organização negra de esquerda, em São Paulo/SP, reuniu jornalistas e universitários negros ligados a Convergência Socialista que atuavam para a libertação e organização do negro no Brasil.

1977. 1a Quinzena do Negro organizada por Eduardo Oliveira e Oliveira, em Campinas/SP.

1978. O ano de 1978 demarcou a passagem dos 90 anos da Abolição com inúmeras manifestações de protesto na conjuntura repressiva do Regime Militar. O Movimento Negro contemporâneo ressurgiu com raízes na esquerda brasileira. O Núcleo Negro Socialista participou ativamente na formação do Movimento Unificado Contra a Discriminação Racial e inaugurou os protestos nas ruas contra a Ditadura Militar, o mito da democracia racial e a violência policial.

1978. Movimento Negro Unificado foi lançado publicamente em 07 de julho de 1978 nas escadarias do Teatro Municipal de São Paulo. Originalmente, foi denominado Movimento Unificado Contra a Discriminação Racial - MUCDR, posteriormente MNU. Em 04 de novembro de 1978, em assembleia dessa organização, foi aprovado o dia 20 de Novembro - dia da morte de Zumbi - como o Dia Nacional da Consciência Negra e a data de 13 de maio como Dia Nacional de Denúncia Contra o Racismo.

1978. Realização do I Festival Comunitário Negro Zumbi (FECONEZU) na cidade de Araraquara, SP.

1978. Fundação da Pastoral Afro-Brasileira que atualmente integra o Conselho Nacional de Promoção da Igualdade Racial da SEPIR - Secretaria de Políticas de Promoção da Igualdade Racial.

1978. Lançamento dos Cadernos Negros - SP.

1978. Fundação do Grupo Nego - BA.

1978. I Congresso Nacional da Anistia. O ativista Milton Barbosa, do Movimento Negro Unificado (MNU) apresenta a tese"O papel do aparato policial do Estado no processo de dominação do negro e a anistia", expondo a problemática da violência policial contra a população negra. 
1978. Lançamento do Manifesto Nacional da Consciência Negra pelo Movimento Unificado contra a Discriminação Racial (MUCDR). O documento foi o ponto de partida do protesto e mobilização de rua da luta contra o racismo. A palavra "consciência negra" convocava a população brasileira a conhecer o conteúdo histórico das lutas da população negra e a atuar na luta contra o racismo.

1979. Fundação do Centro de Cultura Negra do Maranhão $-M A$.

1979. Fundação do Bloco Afro Olodum - BA.

1979. Lei Federal $n^{\circ} 6.767 / 79$ que restabeleceu o pluripartidarismo e inicia a abertura política.

1979. Fundação do Grupo de Mulheres Negras Aqualtune $-\mathrm{RJ}$.

1979. Publicação do livro Discriminação e desigualdades raciais no Brasil, de Carlos Hasenbalg (Ed. Graal)- RJ.

1979. O quesito cor foi incluído no recenseamento do Instituto Brasileiro de Geografia e Estatísticas (IBGE), por pressão de estudiosos e de organizações da sociedade civil organizada.

1980. Censo Demográfico Brasileiro. O Censo Demográfico Brasileiro voltou a coletar informação sobre cor e raça após protestos dos ativistas e intelectuais contra a política de branqueamento da população: branco $(54,77 \%)$, preto $(5,87 \%)$, pardo $(38,45 \%)$ e amarela $(0,63 \%)$.

1980. Fundação do Quilombhoje Literatura - SP.

1980. Fundação do Instituto de Pesquisas e Estudos AfroBrasileiro - IPEAFRO-SP.

1980. Fundação do Legião Rastafári - BA.

1980. Fundação do Grupo de Mulher Negra Luiza Mahin $-\mathrm{RJ}$.

1980. Fundação do Movimento Cultural Filhos de JAH - RJ. 1980. Fundação do Centro de Estudos e Defesa do Negro do Pará - CEDENPA- PA.

1981. Fundação do Grupo União e Consciência Negra do Brasil - RJ.

1982. III Congresso de Cultura Negra das Américas realizado na PUC/SP, sob a presidência de Abdias Nascimento e coordenação de Dulce Pereira.

1983. Fundação dos Agentes de Pastoral Negros do Brasil - APNs - SP.

1983. I Encontro de Mulheres de Favelas e Periferia - RJ que reuniu mulheres negras do Movimento de Favelas,
Movimento de Mulheres e do Movimento Negro o que estimulou a presença da mulher negra na direção das organizações mistas do movimento negro, e a criação de organizações específicas de mulheres negras de caráter popular.

1983. Criação do Nzinga, Coletivo de Mulheres Negras - RJ no dia 16 de junho na sede da Associação de Moradores do Morro dos Cabritos por um grupo de mulheres originárias do Movimento de Favelas e do Movimento Negro. O nome Nzinga remete à rainha Nzinga Mbandi que lutou contra expansionismo português em Angola. O símbolo do pássaro está relacionado à tradição nagô, segundo a qual a ancestralidade feminina é representada por pássaros e as cores, o amarelo com Oxum e o roxo, com o movimento internacional de mulheres. Essas foram as marcas.

1983. Fundação do Coletivo de Mulheres Negras do estado de São Paulo.

1983. Criação do Conselho Estadual da Condição Feminina - SPÉ criado pelo Governo do Estado de São Paulo. Após embate, Tereza Santos, Vera Lucia Santos, Freitas Saraiva e Sueli Carneiro e IIma Fátima de Jesus, militantes do movimento de mulheres negras, foram admitidas na direção.

1984. Fundação do Núcleo Cultural Níger Okán - BA.

1984. Fundação do Grupo homossexuais negros Adê Dudu - BA.

1984. Fundação do Centro Brasileiro de Informação e Documentação do Artista Negro CIDAN - RJ.

1984. Fundação do Grupo Trabalhos e Estudos Zumbi / Tez - MS.

1984. Criação do Conselho de Participação e Desenvolvimento da Comunidade Negra - SP.

1984. Lançamento do Livro O que é racismo de Joel Rufino $-\mathrm{SP}$.

1985. Lélia González e Benedita da Silva integram o Conselho Nacional da Mulher até o ano de 1989.

1985. Promulgada a Lei no $7437 / 85 q u e$ Inclui, entre as contravenções penais a prática de atos resultantes de preconceito de raça, de cor, de sexo ou de estado civil, dando nova redação à Lei no 1.390, de 3 de julho de 1951 - Lei Afonso Arinos.

1986. Tombamento da Serra da Barriga (União dos Palmares, Alagoas), local onde se desenvolveu o Quilombo dos Palmares, o maior refúgio de negros escravizados da América Latina. 
1986. Fundação da Sociedade Afro Sergipana de Estudos e Cidadania (SACI) em Aracaju- SE.

1986. Fundação do Grupo de Mulheres Negras Mãe Andreza - MA.

1986. Fundação do Coletivo de Mulheres Negras de Minas Gerais.

1986. Fundação do Maria Mulher - RS.

1986. Fundação do Coletivo de Mulheres Negras de Minas Gerais.

1986. Fundação do Núcleo de Estudos do Negro NEN - SC. 1986. Lançamento do livro Os Quilombos e a Rebelião Negra de Clovis Moura - SP.

1986. Fundação da Casa de Cultura Afro-Sergipana em Aracaju - SE.

1986. Convenção Nacional do Negro e a Constituinte realizada em Brasília/DF, no mês de Agosto.

1987. Fundação do Instituto do Negro Padre Batista - SP.

1987. Fundação do Núcleo de Consciência Negra na USP $-\mathrm{SP}$.

1987. Lançamento do Livro O Negra Escrito, de Oswaldo de Camargo que trata marginalização editorial de autores negros.

1987. I Encontro de negros do Sul/Sudeste Realizado no Rio de Janeiro.

1987. Fundação do Instituto Nacional da Tradição e Cultura Afro-Brasileiro (INTECAB).

1988. Centenário da Abolição (1988).

1988. Constituição Federal Brasileira - inclui o Artigo 68 ADCT que reconheceu a propriedade definitiva das terras aos remanescentes de quilombos que estivessem ocupando as suas terras; Lei Caó, n 7716 de 1989 que tipifica crime de racismo e altera a Lei Afonso Arinos que punia a infração como uma contravenção penal. Outra importante conquista foi o Voto para o Analfabeto.

1988. Parque Memorial Zumbi dos Palmares criado na Serra da Barriga, na cidade de União dos Palmares, em Alagoas.

1988. Lélia Gonzalez integra o Conselho Nacional da Mulher.

1988. Fundação da União de Negros pela Igualdade (UNEGRO).
1988. Fundação do Grupo de Mulheres do Alto das Pombas - BA.

1988. I Encontro Nacional de Mulheres Negras Realizado no Rio de Janeiro.

1988. Fundação do Geledés: Instituto da Mulher Negra SP.

1988. Sueli Carneiro, do Geledés, integra o Conselho Nacional da Mulher.

1988. Marcha contra a Farsa da Abolição que reuniu cerca de 5.000 pessoas no dia 11 de maio no Rio de Janeiro e enfrentou repressão o Exército.

1988. Fundação Cultural Palmares foi criada pelo Governo Federal.

1988. Fundação do N'zinga - Coletivo de mulheres Negras $-M G$.

1989. Fundação da Comissão de Mulheres Negras de Campinas - SP.

1989. Promulgação da Lei $7.716 / 1989$ (Lei Caó), que define os crimes resultantes de preconceito de raça ou de cor. De acordo com esta lei, Art. 10, Serão punidos, na forma desta Lei, os crimes resultantes de preconceitos de raça ou de cor. Art. 2 (Vetado). Art. 3० Impedir ou obstar o acesso de alguém, devidamente habilitado, a qualquer cargo da Administração Direta ou Indireta, bem como das concessionárias de serviços públicos. Pena: reclusão de dois a cinco anos.

1989. Lançamento do Filme ORI Filme de Raquel Gerber e Beatriz Nascimento documenta a história do movimento negro entre 1978 e 1988. O filme roteirizado pela historiadora e ativista Beatriz Nascimento aborda a organização do movimento negro no tempo e espaço e na relação com sua ancestralidade.

1989. Fundação do Centro de Articulação de Populações Marginalizadas (CEAP) - RJ.

1989. Posse Sindicato Negro, Posse Conceito de Rua, Núcleo Cultural Força Ativa, Movimento Hip-Hop Organizado - MH20. Foram algumas das primeiras organizações do movimento HIP HOP brasileiro - São Paulo.

1989. II Encontro de negros do Sul/Sudeste realizado na cidade de São Paulo.

1989. X Encontro de Negros do Norte/ Nordeste realizado na cidade de Salvador, na Bahia.

1989. I Encontro de Negros do Centro-Oeste realizado na cidade de Goiânia, em Goiás. 
1990. Censo Demográfico Brasileiro traz dados importantes sobre a pirâmide etária da população negra, por sexo no Brasil - 1980/1991.

\section{Fundação do Grupo Afro-Cultural Coisa de Nêgo em} Teresina/PI.

1990. Estatuto da Criança e Adolescente - ECA, criado por meio da Lei n. 8.069, define que nenhuma criança ou adolescente pode sofrer qualquer forma de discriminação.

1990. Libertação de Nelson Mandela - África do Sul.

1990. Fundação do Coletivo de Mulheres Negras de Salvador - Bahia.

1990. Fundação do Centro de Estudos das Relações de Trabalho e Desigualdades(CEERT) - SP.

1990. Fundação da Casa de Cultura da Mulher Negra de Santos - SP.

1990. III Encontro de negros do Sul/ Sudeste realizado na cidade de Vitória, no Espírito Santo.

1990. Fundação da União dos Negros de Aracaju - SE.

1991. $1^{\circ}$ Encontro Nacional de Entidades Negras (ENEN) que ocorreu em novembro, em São Paulo, após a realização dos Encontros Regionais do Negro do Norte e Nordeste, do Sul e Sudeste e do Centro-Oeste.

1991. Fundada a Coordenação Nacional das Entidades Negras (CONEN), em novembro é uma organização nacional de articulação, elaboração e intervenção na luta de combate ao racismo no Brasil. Integra o Conselho Nacional de Promoção da Igualdade Racial da SEPPIR desde a sua criação.

1991. II Encontro Nacional de Mulheres Negras realizado na cidade de Salvador, na Bahia.

1991. I Encontro de Mulheres Negras do MNU realizado na cidade de Recife, em Pernambuco.

1991. Criação da Secretaria Extraordinária de Defesa e Promoção das Populações Negras que foi criada no Governo do Estado do Rio de Janeiro, chefiada por Abdias Nascimento.

1991. Fundação do Centro Nacional de Religiosidade e Africanidade Afro- Brasileiro, CENARAB/MG.

1991. Fundação da Soweto Organização Negra - SP.

1991. Fundação NEAB - UFSCar - SP.

1992. Fundação da Sociedade Comunitária Ecológica Cultural e Escola de Samba Fala Negão - SP.
1992. Lançamento Livro Há um Buraco Negro entre a Vida e a Morte. Livro de Arnaldo Xavier na ECO 92-Conferência da ONU sobre Meio Ambiente e Desenvolvimento, realizada na cidade do Rio de Janeiro. Diversas organizações do movimento negro brasileiro e internacional participam dessa Conferência.

1992. Fundação do Grupo Criola-RJ.

1992. Fundação do Instituto Cultural Steve Biko-BA.

1992. Criação da Coordenadoria dos Assuntos da População Negra CONE - SP.

1993. Fundação do Educafro - Educação e Cidadania de Afrodescendentes e Carentes.

1993. Criação do Movimento dos pré-vestibulares para negros e carentes - RJ.

1993. Seminário Nacional: Negros Universitários (SENUN). Realizado na cidade de Salvador, na Bahia.

1993. Fundação do Grupo Cultural Afro Reggae - RJ.

1994. Fundação da Comissão Nacional de Combate à Discriminação Racial da CUT.

1994. Fundação da Malungus - Organização Negra da Paraíba - PB.

1994. Fundação do Coletivo de Mulheres Negras Esperança Garcia - PI.

1994. Fundação do grupo cultural Questão Ideológica/QI. Teresina - PI

1995. Tricentenário da morte de Zumbi dos Palmares. O ano do Tricentenário da morte de Zumbi dos Palmares dá início à fase de politização nacional da luta antirracista. O estado brasileiro é denunciado como indutor das desigualdades sociorraciais. Somente em 2002 com a vitória do PT e do projeto de um governo popular e democrático abriu-se caminho para a democratização do Estado, a efetivação da igualdade e a cidadania dos negros.

1995. Marcha Zumbi Contra o Racismo pela Cidadania e a Vida em Brasília/DF.

1995. Fundação do grupo Afro-Condarte - Teresina - PI.

1995. Fundação do IFARADÀ - Núcleo de Estudos e Pesquisas em Africanidades e Afrodescendências da UFPI. Vale lembrar que o núcleo foi criado em 1993, por um grupo de estudantes negros. Primeiramente foi intitulado de grupo MIMBÓ, em homenagem a uma comunidade negra rural, localizada no município de Amarante, Piauí. 
Mas, somente em 20 de Novembro de 1995, foi aprovado por resolução do conselho universitário da UFPI.

1995. Fundação do Movimento Pela Paz na Periferia/MP3 - Teresina - PI.

1995. Congresso Continental dos Povos Negros das Américas, realizado nos dias 21 a 25 de Novembro, em São Paulo.

1995. Primeira titulação de terra de quilombola em Oriximiná no Estado do Pará.

1995. Fundação do Instituto Sindical Interamericano Pela lgualdade Social (INSPIR) que reúne CUT, CGT, FS, AFLCIO e ORIT.

1995. Fundação do CEAFRO - UFBA.

1995. Fundação do Coletivo de Mulheres Negras do Mato Grosso do Sul.

1995. Fundação da Associação de Mulheres Negras Otorrin. Dudu - ES.

1995. Fundação do Congresso Nacional Afro-Brasileiro (CNAB).

1995. I Encontro Nacional de Comunidades Negras Rurais Quilombolas realizado em novembro, em Brasília/DF.

1996. Fundação do Jornal IROHIN - DF.

1996. Fundação do Núcleo de Estudos e Pesquisas Interdisciplinares sobre o Negro Brasileiro (NEINB) - SP.

1996. Fundação da Coordenação Nacional de Quilombos (CONAQ).

1996. Reconhecimento Oficial de Zumbi dos Palmares como herói nacional no panteão dos Heróis da Pátria através de medida legislativa aprovada em 21/03/1997.

1996. Fundação do Oriashé Sociedade Brasileira de Cultura e Arte Negra de São Paulo - SP.

1997. Associação das Comunidades Negras Rurais Quilombolas do Maranhão - ACONERUQ-MA.

1997. Abdias Nascimento assume o mandato de senador pelo PDT-RJ após a morte do titular Darcy Ribeiro.

1997. Fundação da Fala Preta! Organização de Mulheres Negras - SP.

1997. Fundação do Coletivo Empresários e Empreendedores Afro-Brasileiros (CEABRA) - SP.

1998. Fundação da Associação Pró-Falcêmicos Anemia falciforme - SP.

1998. Criação do Sistema de Cotas na Universidade de Brasília (UnB), a partir do Caso Ari. O estudante de Engenharia Civil Arivaldo Lima Alves, negro, foi o único aluno reprovado em um projeto, apesar de ter as melhores notas.

1999. Criação da Frente Parlamentar em Defesa da Igualdade Racial no Congresso Nacional.

1999. Fundação da Casa do HIP HOP Diadema - SP.

1999. Fundação Centro de Referência da Cultura Negra de Minas Gerais.

1999. II Encontro Nacional de Entidades Negras realizado na cidade do Rio de Janeiro, com o tema "500 anos de racismo em tempos de globalização e exclusão social".

1999. Fundação do Grupo de Mulheres Negras Malungas $-\mathrm{GO}$.

1999. Fundação da Associação Nacional do Coletivo de Empresário e Empreendedor Afro-Brasileiro (ANCEABRA).

2000. Fundação do Fórum Nacional de Mulheres Negras.

2000. Fundação da Articulação de Organizações das Mulheres Negras Brasileiras (AMNB).

2000. II Encontro Nacional das Comunidades Negras Rurais Quilombolas realizado de 29 de novembro a 03 de dezembro, na cidade de Salvador, na Bahia.

2000. Censo Demográfico Brasileiro evidenciou o declínio da política de branqueamento da população brasileira e registra dados significativos da desigualdade sociorracial fortalecendo proposta de ação governamental das políticas de ações afirmativas.

2000. Fundação do Instituto de Mulheres Negras do Amapá (IMENA).

2000. Feriado Estadual da Consciência Negra - 20 de Novembro- RJ. Posteriormente muitos municípios decretaram feriados por pressão reivindicatória do movimento negro local.

2000. O Movimento Nacional de Resistência Indígena, Negra e Popular realiza a Marcha Brasil outros 500Marcha contra o racismo e as desigualdades sociais, no dia 22 de Abril, demarcando os protestos contra as festividades comemorativas dos 500 anos do descobrimento do Brasil em Porto Seguro, na Bahia.

2000. Fundação da Kilombo - Organização Negra do Rio Grande do Norte- RN.

2000. Fundação da Associação Brasileira de Pesquisadores Negros (ABPN). 
2000. Fundação da Bamidelê - Organização de Mulheres Negras - PB.

2001. III Conferência Mundial contra o racismo, a discriminação, a xenofobia e formas de intolerâncias correlatas, promovida pela ONU de 31 de Agosto a 08 de setembro de 2001 na cidade de Durban, na África do Sul. No início do Século XXI a luta contra o racismo se massifica e adquire maior visibilidade internacional.

2001. III Encontro Nacional de Mulheres Negras realizado no mês de julho na cidade de Belo Horizonte, no Estado de Minas Gerais.

2001. Declaração de Durban Adotada em 08 de setembro de 2001 em Durban, África do Sul.

2002. Cotas raciais através das Leis: $3.524 / 2000$ e 3.708/2001UERJ institui reserva de vagas: $50 \%$ para candidatos oriundos da rede pública de ensino e $40 \%$ para candidatos que se declaram pretos(as) ou pardos(as) - RJ.

2003. A Lei 10639/2003, que alterou a LDB 9394/1996 e incluiu no currículo oficial da rede de ensino pública e privada a disciplina de História e Cultura Afro-Brasileira e Africana. Esse foi primeiro ato do Presidente Lula honrando seus compromissos eleitorais com a comunidade negra.

2004. Publicação das Diretrizes Curriculares Nacionais para a Educação das Relações Étnico-Raciais e para o Ensino de História e Cultura Afro-Brasileira e Africana.

2004. Parecer CNE/CP 003/2004 e a Resolução CNE/CP 01/2004.

2005. Fundação do Coletivo de Entidades Negras (CEN).

2005. Zumbi +10 II Marcha contra o Racismo, pela Igualdade e a Vida. De acordo com as fontes pesquisadas, a Marcha Zumbi + 10 foi organizada por centrais sindicais e entidades não-governamentais de todo o Brasil, e contou com a participação de representantes dos estados de Tocantins, Acre, Amazonas, São Paulo, Espírito Santo, Bahia, Rio Grande do Sul, Ceará, Pernambuco, Maranhão, Alagoas, Mato Grosso do Sul, Goiás, Paraná, Distrito Federal e outros. Presentes também representantes das universidades federais de Uberlândia (UFU/MG) e Rural de Pernambuco (UFRPE), e a secretária de Educação de Salvador, Olívia Santana.

Duas marchas são realizadas, uma no dia 16 e a outra no dia 22 de novembro, em Brasília/DF, organizada pelas seguintes entidades do Movimento Negro brasileiro: Agentes de Pastoral Negros (APNs), Centro de Articulação das Populações Marginalizadas (CEAP), Articulação Nacional do Coletivo de Empresários e
Empreendedores Afro-Brasileiros (ANCEABRA), Centro Nacional de Cidadania Negra, Comissão Nacional contra a Discriminação Racial da Central Única dos Trabalhadores (CNCDR/CUT), Congresso Nacional Afro-Brasileiro (CNAB), Conselho Nacional de Yalorisas, Egbomis e Ekédis Negras, Coordenação Nacional de Entidades Negras (CONEN), Fórum Nacional de Mulheres Negras, Instituto Nacional da Tradição e Cultura Afro- Brasileira (INTECAB), Movimento Nacional Fala Bantu, Movimento Negro Unificado (MNU), Setorial de Negros e Negras da Central de Movimentos Populares (CMP), União de Negros pela Igualdade (UNEGRO), Unidade de Mobilização Nacional pela Anistia.

Duas marchas, histórico: em congressos anteriores, a de preparação da marcha, houve sérias discordâncias acerca dos fundos para a realização da mesma O ponto de impasse era: aceitava-se ou não fundos governamentais. Como decorrência disso, duas marchas foram organizadas: uma para o dia 16 de Novembro por aqueles que não aceitaram financiamento do governo e apostava na organização autônoma da luta negra. A outra, no dia 22, daquele mesmo mês para grupos financiados pelo governo. Durante a marcha do dia 16, o que mais se gritava era "se hoje estou (negro/a) aqui, só devo a Dandara, só devo a Zumbi".

2005. I Conferência Nacional de Promoção da Igualdade Racial (CONAPIR).

2005. Portaria nº $4542 / 2005$ cria a Comissão Técnica Nacional de Diversidade para Assuntos da Educação dos Afro-Brasileiros-CADARA.

2006. Fundação da Rede Amazônia Negra - AP.

2006. Criação do Laboratório de Análises Econômicas, Históricas, Sociais e Estatística das Relações Raciais (LAESER) vinculado ao Instituto de Economia da Universidade Federal do Rio de Janeiro (IE/UFRJ) e coordenado pelo economista Marcelo Paixão - RJ.

2007. Encontro Nacional da Juventude Negra - ENJUNE realizado nos dias 27 a 29 de julho na cidade de Lauro de Freitas, na Bahia, com o tema "Novas perspectivas na militância étnico-racial". Este encontro foi precedido de encontros estaduais reuniu cerca de 800 pessoas entre delegados, coordenadores e convidados.

2008. Fundação da Comissão Nacional de Jornalistas pela Igualdade Racial (CONAJIRA). Atualmente integra o Conselho Nacional de Promoção da Igualdade Racial da SEPIR.

2008. Criação da Diretoria Combate ao Racismo da União Nacional dos Estudantes (UNE). Atualmente integra o 
Conselho Nacional de Promoção da Igualdade Racial da SEPPIR.

2008. Lei $n^{\circ} 11.645$, de 10 de março de 2008. Altera a Lei no 9.394, de 20 de dezembro de 1996, modificada pela Lei no 10.639, de 09 de janeiro de 2003, que estabelece as diretrizes e bases da educação nacional, para incluir no currículo oficial da rede de ensino a obrigatoriedade da temática "História e Cultura Afro-Brasileira e Indígena".

2009. Plano Nacional de Implementação das Diretrizes Curriculares Nacionais para a Educação das Relações Étnico-Raciais e para o Ensino de História e Cultura AfroBrasileira e Africana.

2009. II Conferência Nacional de Promoção da Igualdade Racial realizada nos dias 25 a 28 de Junho, em Brasília/DF.

2009. Fundação do Instituto da Mulher Negra do Piauí/ AYABÁS - Teresina - PI.

2010. Aprovado o Estatuto da Igualdade Racial, por meio da Lei $n^{\circ} 12.288$ de julho/2010, que garante igualdade de oportunidade e dos direitos à população negra e o combate à discriminação e às formas de intolerância étnica que prevê o estabelecimento de políticas públicas de valorização da cultura negra para a correção das desigualdades provocadas pelo sistema escravista no País.

2010. Censo Demográfico Brasileiro revelou, pela primeira vez na História do Censo, que a população preta, parda, indígena e amarela superou a população branca que constitui apenas $47,73 \%$ da população brasileira e registra dados significativos da desigualdade sociorracial.

2011. Parecer CNE/CEB No: 14/2011. Define as Diretrizes para o atendimento de educação escolar de crianças, adolescentes e jovens em situação de itinerância.

2012. A Lei $n^{\circ} 12.711 / 2012$, sancionada em agosto deste ano, garante a reserva de $50 \%$ das matrículas por curso e turno nas 59 universidades federais e 38 institutos federais de educação, ciência e tecnologia a alunos oriundos integralmente do ensino médio público, em cursos regulares ou da educação de jovens e adultos. Os demais $50 \%$ das vagas permanecem para ampla concorrência. A Lei 12.711 define que, até 2016, as instituições federais de ensino superior devem reservar $50 \%$ das vagas para estudantes autodeclarados pretos, pardos, indígenas (conforme definições usadas pelo Instituto Brasileiro de Geografia e Estatística (IBGE)), de baixa renda (de famílias com renda igual ou inferior a 1,5 salário mínimo per capita) e tenham cursado o ensino médio em escolas públicas. O número de cotas para pretos, pardos e indígenas é estipulado conforme a proporção dessa população em cada estado, segundo último censo do IBGE.
2012. Manifesto em defesa das ações afirmativas e das cotas raciais para a população negra, povos indígenas e alunos egressos das escolas públicas brasileiras foi realizada uma audiência pública sobre a Constitucionalidade de Políticas de Ação Afirmativa de Acesso ao Ensino Superior, pelo Supremo Tribunal Federal (STF), nos dias 3 a 5 de Março, em Brasília, no Distrito Federal.

2012. Resolução CNE/CEB n 8, de 20 de Novembro de 2012 que define Diretrizes Curriculares Nacionais para a Educação Escolar Quilombola na Educação Básica.

Diretrizes Curriculares Nacionais para a Educação Escolar Quilombola.

2013. Portaria Normativa MEC $n^{\circ} 21$, de 28 de agosto de 2013 D.O.U.: 30/08/2013. Dispõe sobre a inclusão da educação para as relações étnico-raciais, do ensino de História e Cultura Afro-Brasileira e Africana, promoção da igualdade racial e enfrentamento ao racismo nos programas e ações do Ministério da Educação, e dá outras providências.

Fonte: Elaboração própria.

\section{Conclusão: marcos positivos para o Movi- mento Social Negro Brasileiro}

O quadro acima não é tudo que existe enquanto produção, eventos e organização de iniciativa negra do país. No entanto, é uma amostra significativa e que compõe todos os campos da história desta nação. Os diversos grupos de africanos que desembarcaram em terras brasileiras na condição de escravo foram submetidos ao trabalho compulsório, além de trazer importantes conhecimentos e deixar sua marca em cada canto desse país, montaram estratégias de resistência e, com suas bandeiras de luta que vão desde a denúncia contra o racismo e suas consequências, a proposição de políticas públicas que atendessem as suas especificidades e até mesmo a composição do governo central.

É fato que, na modernidade, o Brasil se desponta entre as maiores economias do mundo e foi considerado, ao longo de muitas décadas, o país da "democracia racial". Todavia, precisou se ajustar e admitir que tal democracia ocorria tão somente no campo jurídico, pois, no convívio entre as pessoas e nas experiências cotidianas, continuava a ser um país racista, com políticas públicas universalistas e segregacionistas. É sabido, também, que, embora nunca 
tenha se consolidado no país um regime de segregação racial legal e formal, a realidade brasileira demonstra outra face. As distinções e desigualdades raciais são contundentes, facilmente visíveis e de graves consequências para a população afrodescendente e para o país como um todo.

É contra as profundas desigualdades e visíveis distorções entre negros e brancos que o Movimento Social Negro, nas suas diversas faces e fazes, vem lutando ao longo da sua história.

O cronograma ora denominado neste artigo de "marcos positivos" demonstra não somente a luta de um povo pelo reconhecimento da sua existência, da sua força de trabalho, das suas potencialidades, da origem e etnicidade enquanto particularidades positivas e singulares a cada um enquanto ser humano.

Por fim, é possível identificar com base no quadro de eventos e instituições ligados aos afrobrasileiros o Movimento Negro nas suas multifaces como um segmento que, ao longo da sua história de luta, desponta no século XXI imprimindo passos importantes, pois, muito além de seguir o fluxo da história em termos de mudanças culturais, promoveu, também, mudanças estruturais, mesmo com sutileza é visível, tendo em vista seu ponto de partida.

As marcas do Movimento Social Negro estão impressas em todas as esferas sociais quando reconhecemos os avanços alcançados nos aparatos normativos do Estado brasileiro no que diz respeito à promoção da igualdade racial. Porém, é preciso que esse Estado, além de reconhecer a legitimidade desse Movimento Social, busque a sua parceria para implementar as políticas públicas afirmativas, resultado das lutas de muitos homens e mulheres negras desse país.

Por fim, Élio Ferreira (2006, p. 53), pesquisador Piauiense, nos fala em versos: "me rebelei, matei o Senhor, a Sinhá, o Sinhozinho, a Sinhozinho, o feitor, o capitão-do-mato e me refugiei nos quilombos".

Assim como na ficção de Ferreira, a dinâmica da vida real também deixa um caminho com pegadas e memórias que chamamos, neste artigo, de saberes. A história extraída dessas memórias não traz exatidão, ela vai seguindo o caminho da memória e tecendo histórias. Sempre que um homem ou uma mulher atravessa uma estrada, saem os dois diferentes. Nem a estrada será a mesma, nem a mulher ou o homem serão os mesmos.
Assim são os homens e as mulheres. Assim deve fazer o Estado. Se moldar à sociedade para melhor atender às suas demandas.

\section{Referências}

BRASIL. Constituição (1988). Constituição da República Federativa do Brasil. 23. ed. Brasília: Senado Federal, 2004.

BRASIL. Câmara dos Deputados. Lei n. 1390, de 3 de julho de 1951. Disponível em: <http://www2.camara.leg.br/ legin/fed/lei/1950-1959/lei-1390-3-julho-1951-361802normaatualizada-pl.html>. Acesso em: 12 fev. 2014.

BRASIL. Câmara dos Deputados. Decreto-lei n. 37, de 2 de dezembro de 1937. Disponível em: <http://www2. camara.leg.br/legin/fed/declei/1930-1939/decreto-lei37-2-dezembro-1937-354175-publicacaooriginal-1-pe. html>. Acesso em: 12 fev. 2014.

BRASIL. Leis etc.: Coleção das Leis do Brasil de 1808. Rio de Janeiro: Imprensa Nacional, 1891.

BRASIL. Ministério da Cultura. A Fundação Cultural Palmares na III Conferência Mundial sobre o Racismo, Xenofobia e Intolerâncias Correlatas. Brasília: MinC, 2002.

BRASIL. Lei n. 7437, de 20 de dezembro de 1985. Disponível em: <http://www.planalto.gov.br/ccivil_03/ Leis/L7437.htm>. Acesso em: 25 fev. 2014.

BRASIL. Lei n. 7716, de 5 de janeiro de 1989. Disponível em: <http://www.planalto.gov.br/ccivil_03/leis/17716. htm>. Acesso em: 25 fev. 2014.

BRASIL. Secretaria de Educação Fundamental. Lei de Diretrizes e Bases da Educação Nacional (LDB) - Lei $n^{\circ}$ 9.394, de 20.12.96. Brasília: Ministério da Educação e Cultura, 1996.

CANDAU, Vera Maria (Coord.). Somos tod@s iguais? Escola, discriminação e educação em direitos humanos. Rio de Janeiro: DP\&A, 2003.

CARDOSO, Marcos Antônio. O movimento negro em Belo Horizonte: 1978-1998. Belo Horizonte: Mazza, 2002.

CASA COMUM. [Homepage]. Disponível em: <http:// casacomum.org/cc/arquivos?set=e_4031/p_2\#!e_3986>. Acesso em: 25 fev. 2014.

INSTITUTO BRASILEIRO DE GEOGAFIA E ESTATÍSTICA. Censo demográfico 1940-1970. Rio de Janeiro: IBGE, 1950-1973.

CUNHA JUNIOR, Henrique. Me chamaram de macaco e eu nunca mais fui à escola. In: GOMES, Ana Beatriz; CUNHA JUNIOR, Henrique (Orgs.) Educação $e$ afrodescendência no Brasil. Fortaleza: UFC, 2008. 
DIAS, Lucimar Rosa. Quantos passos já foram dados? A questão de raça nas leis educacionais: da LDB de 1961 à Lei 10.639 de 2003. In: ROMÃO, Jeruse (Org.) História da educação do negro e outras histórias. Brasília: MEC/ SECAD, 2005. p. 49-62.

DOMINGUES, Petrônio. Movimento Negro Brasileiro: alguns apontamentos históricos. Revista Tempo, n. 23, p. 100-122, 2007. Disponível em: <http://www.scielo. $\mathrm{br} / \mathrm{pdf} / \mathrm{tem} / \mathrm{v} 12 \mathrm{n} 23 / \mathrm{v} 12 \mathrm{n} 23 \mathrm{a} 07 . \mathrm{pdf}>$. Acesso em: $25 \mathrm{fev}$. 2014.

EVARISTO, Conceição. Eu não sei cantar: entrevista com Conceição Evaristo. Revista Raça, n. 96, mar. 2006. Disponível em: <http://racabrasil.uol.com.br/Edicoes/96/ artigo15620-3.asp >. Acesso em: 24 fev. 2014.

SOUZA, Elio Ferreira de; WALTER, Roland Gerhard Mike. Poesia negra das Américas: Solano Trindade e Langston Hughes. 2006. Tese (Doutorado) - Programa de Pós-Graduação em Letras, Universidade Federal de Pernambuco, Recife, 2006.

GELEDES. Brazilian Black Front: frente negra brasileira. Disponível em: <http://www.geledes.org.br/atlanticonegro/afrobrasileiros/frente-negra-brasileira/11052brazilian-black-front-frente-negra-brasileira-englishversion>. Acesso em: 25 fev. 2014.

GEBRIM, Sophia. Cultura africana chega às escolas de educação profissional, 2006. Disponível em: $<$ http://portal.mec.gov.br/index.php?option $=$ com content\&view $=$ article\&id $=6340 \&$ catid $=209>$. Acesso em: 20 out. 2015 .

GOMES, Nilma Lino. O movimento negro no Brasil: ausências, emergências e a produção dos saberes. Dossiê Política e Sociedade, Santa Catarina, v. 10, n. 18, abr. 2011.

HENRY, Paget. Caliban's reason: introducing afrocaribbean philosophy. New York: Routledge, 2000.

LAFER, Celso. A reconstrução dos direitos humanos: um diálogo com Hannah Arendt. São Paulo: Cia. das Letras, 1999.

LIMA, Ivaldo Marciano de França. Negro, mostra sua cara! Disponível em: <http://negritudepernambucana. blogspot.com.br/2010/04/negro-mostra-sua-caramovimento-negro.html>. Acesso em: 20 fev. 2014.

MOORE, Carlos Wedderburn. Novas bases para o ensino da História da África no Brasil. In: EDUCAÇÃO Antirracista: caminhos abertos pela lei federal $n^{\circ}$. 10.639/03. Brasília: Ministério da Educação/Secretaria de Educação Continuada/Alfabetização e Diversidade, 2005. (Coleção Educação para Todos).
MOURA, Clóvis. Rebeliões da senzala: quilombos, insurreições, guerrilhas. Porto Alegre: Mercado Aberto, 1988.

MOVIMENTO NEGRO UNIFICADO. [Homepage]. Disponível em: <http://movimentonegrounificadomnu. blogspot.com.br/2007/05/13-de-maio-dia-nacional-dedenncia.html>. Acesso em: 25 fev. 2014.

NASCIMENTO, Abdias. Abrindo caminhos, construindo novos espaços de afirmação: ações afirmativas para a população negra brasileira na educação profissional e tecnológica. Curitiba: Appris, 2011.

NASCIMENTO, Abdias. Teatro experimental do negro: trajetória e reflexões. Estudos Avançados, São Paulo, v. 18, n. 50, p. 209-224, abr. 2004. Disponível em: <http://www. scielo.br/scielo.php>. Acesso em: 25 fev. 2014.

ORGANIZAÇÃO INTERNACIONAL DO TRABALHO. Discriminação em matéria de emprego e ocupação. Disponível em: <http://www.oitbrasil.org.br/node/472>. Acesso em: 25 fev. 2014.

PEREIRA, Amauri Mendes. Trajetória e perspectivas do Movimento Negro Brasileiro. 2. ed. Belo Horizonte: Nandyala, 2008.

PEREIRA, Amauri Mendes; ARAÚJO, Amilcar. O mundo negro: a constituição do movimento negro contemporâneo brasileiro (1970 a 2005). Rio de Janeiro: UFF, 2010.

REIS, João José; SILVA, Eduardo. Negociação e conflito: a resistência negra no Brasil escravista. Rio de Janeiro: Companhia das Letras, 1989.

ROSA, Bárbara da Silva; MIDLEJ, Suylan. Fóruns de educação e diversidade étnico-racial: condicionantes legais para a participação social nas políticas públicas educacionais. Pensamento \& Realidade: Revista do Programa de Estudos Pós-Graduados em Administração, PUC-SP, v. 27, p. 79-94, 2012.

SANTOS, Joel Rufino dos. Movimento negro e crise brasileira, atrás do muro da noite: dinâmica das culturas afro-brasileiras. Brasília: Ministério da Cultura/Fundação Cultural Palmares, 1994.

SCHERER-WARREN, Ilse. Movimentos sociais: um ensaio de interpretação sociológica. 2. ed. Florianópolis: UFSC, 1987.

SHERIFF, Robin. Negro é um apelido que os brancos deram aos pretos. Rio de Janeiro: UFRJ, 1995.

SILVA JUNIOR, Hédio. Antirracismo: coletânea de leis brasileiras - federais, estaduais e municipais. São Paulo: O. Mendes, 1988. 
SILVA, Iraneide Soares da. A trajetória dos estudos de relações raciais no Brasil. Padê: Estudos em Filosofia, Raça, Gênero e Direitos Humanos, Brasília, v. 2, n. 1, semestral, 2007.

SILVA, Iraneide Soares da. As inquietações no currículo educacional a partir da Lei 10639/03. Padê: Estudos em Filosofia, Raça, Gênero e Direitos Humanos, Brasília, v. 1, n. 2, p. 33-51, semestral, 2007.
SILVA, Joselina. Homens de cor: uma rede do movimento negro após o Estado Novo. 2005. Tese (Doutorado) Ciências Sociais, Universidade Estado do Rio de Janeiro, Rio de Janeiro, 2005.

THEODORO, Mário. (Org.) As políticas públicas e a desigualdade racial no Brasil 120 anos após a abolição. Brasília: IPEA, 2008. 